\title{
Asymmetric GaAs/AIGaAs T wires with large confinement energies
}

\author{
Gislason, Hannes; Langbein, Wolfgang Werner; Hvam, Jørn Märcher
}

Published in:

Applied Physics Letters

Link to article, DOI:

$10.1063 / 1.118025$

Publication date:

1996

Document Version

Publisher's PDF, also known as Version of record

Link back to DTU Orbit

Citation (APA):

Gislason, H., Langbein, W. W., \& Hvam, J. M. (1996). Asymmetric GaAs/AIGaAs T wires with large confinement energies. Applied Physics Letters, 69(21), 3248-3250. https://doi.org/10.1063/1.118025

\section{General rights}

Copyright and moral rights for the publications made accessible in the public portal are retained by the authors and/or other copyright owners and it is a condition of accessing publications that users recognise and abide by the legal requirements associated with these rights.

- Users may download and print one copy of any publication from the public portal for the purpose of private study or research.

- You may not further distribute the material or use it for any profit-making activity or commercial gain

- You may freely distribute the URL identifying the publication in the public portal

If you believe that this document breaches copyright please contact us providing details, and we will remove access to the work immediately and investigate your claim 


\title{
Asymmetric GaAs/AIGaAs $T$ wires with large confinement energies
}

\author{
H. Gislason, W. Langbein, a) and J. M. Hvam \\ Mikroelektronik Centret, The Technical University of Denmark, Building 345e, DK-2800 Lyngby, Denmark
}

(Received 22 July 1996; accepted for publication 12 September 1996)

\begin{abstract}
We report on the design and growth of asymmetric $T$-shaped quantum wires with large one-dimensional confinement energies. Prior to growth, the optimal structure for a given (110) well width is determined by a calculation. The structures are made by molecular beam epitaxy cleaved edge overgrowth. We demonstrate a confinement of $54 \mathrm{meV}$ in an experimental structure consisting of a narrow (110) oriented $\mathrm{GaAs} / \mathrm{Al}_{0.3} \mathrm{Ga}_{0.7} \mathrm{As}$ quantum well overgrown on much wider (001) oriented $\mathrm{Al}_{0.14} \mathrm{Ga}_{0.86} \mathrm{As} / \mathrm{Al}_{0.3} \mathrm{Ga}_{0.7} \mathrm{As}$ wells. (c) 1996 American Institute of Physics. [S0003-6951(96)03747-3]
\end{abstract}

One-dimensional wire states confined at the intersection between (001) and (110) oriented GaAs/AlGaAs quantum wells ( $T$ wires) are predicted to have enhanced exciton binding energies and oscillator strengths compared to twodimensional structures. ${ }^{1}$ These one-dimensional structures have been realized by the cleaved edge overgrowth technique $^{2}$ with monolayer precision determined by the molecular beam epitaxy (MBE) growth technology. The fundamental properties of the one-dimensional systems together with their potential device applications have led to a strong interest in the growth and optimization of these structures. ${ }^{3-6}$

The size of the one-dimensional confinement energy is of great importance for device applications at room temperature. The highest $T$-wire confinement energies reported are, to our knowledge, $28 \mathrm{meV}$ for asymmetric GaAs/AlGaAs $T$-wire with $\mathrm{Al}$ in the (001) wells ${ }^{4}$ and $38 \mathrm{meV}$ for asymmetric GaAs/AlAs $T$ wires. ${ }^{7}$

We present in this work an optimization of asymmetric GaAs/AlGaAs $T$ wires with a low concentration of $\mathrm{Al}$ in the (001) wells and reach a $T$-wire confinement energy of 54 $\mathrm{meV}$, which is significantly higher than $\mathrm{kT}$ at room temperature. We pre-design the sample parameters by a calculation of the confined $T$-wire states. ${ }^{8}$ The calculations are based on an effective mass approach for the conduction band states and a six-band $\mathbf{k} \cdot \mathbf{p}$ model for the valence band states. Here we show, in Fig. 1(a), the results for the transition energies of asymmetric $T$ wires with $\mathrm{Al}_{0.3} \mathrm{Ga}_{0.7} \mathrm{As}$ barriers. The calculations are made for $T$ wires with 3- and 5-nm-wide overgrown GaAs wells. For a given overgrown well width, the transition energy of the $T$ wires is evaluated as a function of the (001) oriented $\mathrm{Al}_{x} \mathrm{Ga}_{1-x} \mathrm{As}$ well width. The $\mathrm{Al}$ content $(x)$ of the (001) wells, shown in Fig. 1(b), is adjusted for each well width so that the transition energy of the (001) wells coincides with the transition energy of the (110) well, indicated by the solid horizontal lines in Fig. 1(a). The highest one-dimensional confinement energy is found where the separation between the transition energy of the $T$ wires and the wells is largest.

The general trend, seen in Fig. 1(a), is that the $T$-wire transition energy is lowered with increasing (001) well width until a second confined $T$-wire state appears with higher energy. In this case, the effective confinement is reduced to the

${ }^{\text {a)} E l e c t r o n i c ~ m a i l: ~ l a n g b e i n @ m i c . d t u . d k ~}$ separation between the first and second $T$-wire state. Therefore, we choose a sample design with only one $T$-wire state. The optimized sample parameters are taken from Figs. 1(a) and 1(b), and the corresponding structures are shown in Fig. 1(c). In this way, we expect one-dimensional confinement energies of $26 \mathrm{meV}$ for the $5 \mathrm{~nm}$ overgrowth and $34 \mathrm{meV}$ for the $3 \mathrm{~nm}$ overgrowth.

Using MBE, we have grown two asymmetric $T$-wire samples (ASW1 and ASW2) similar to the calculated optimized structures, which are 3 and $5 \mathrm{~nm}$ (110) GaAs/ $\mathrm{Al}_{0.3} \mathrm{Ga}_{0.7} \mathrm{As}$ quantum wells overgrown on $120 \AA$ $\mathrm{Al}_{0.12} \mathrm{Ga}_{0.88} \mathrm{As} / \mathrm{Al}_{0.3} \mathrm{Ga}_{0.7} \mathrm{As}$ and $180 \AA \mathrm{Al}_{0.07} \mathrm{Ga}_{0.93} \mathrm{As} /$ $\mathrm{Al}_{0.3} \mathrm{Ga}_{0.7} \mathrm{As}(001)$ oriented multiple quantum wells, respectively.

The growth of the (001) structure is somewhat compli-
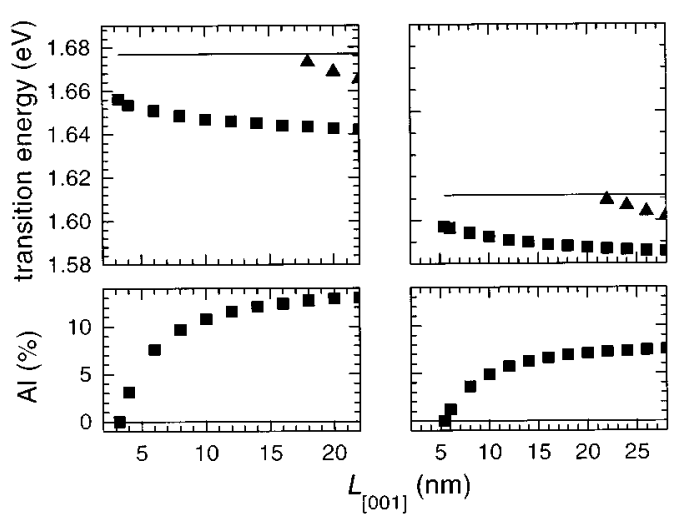

(a)

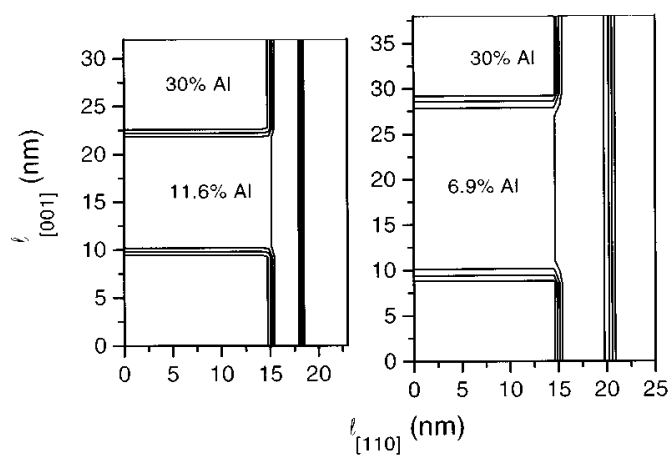

(c)

FIG. 1. Calculated transition energies (a) and $\mathrm{Al}$ contents (b) of $T$ wires with $3 \mathrm{~nm}$ (left) and $5 \mathrm{~nm}$ (right) (110)-GaAs/ $\mathrm{Al}_{0.3} \mathrm{Ga}_{0.7} \mathrm{As}$ overgrowth for different (001) $\mathrm{Al}_{x} \mathrm{Ga}_{1-x} \mathrm{As}_{\mathrm{Al}} \mathrm{Al}_{0.3} \mathrm{Ga}_{0.7} \mathrm{As}$ well widths. The optimized sample structures are shown in (c). 
cated by the low $\mathrm{Al}$ content in the wells. Having only one Al cell in the MBE growth chamber, this structure can either be made by growth interrupts, while the temperature of the $\mathrm{Al}$ cell is changed between the growth of the barriers and the growth of the wells, or by keeping the temperature of the $\mathrm{Al}$ cell fixed and rapidly operating the shutter of the Al cell, thus forming a digital alloy (DA) in the wells. ${ }^{4}$ We chose the latter approach to avoid surface contamination during growth interrupts. However, it imposes an inaccuracy in the value of the $\mathrm{Al}$ content in the wells, because the nominal $\mathrm{Al}$ shutter time is comparable to the shutter switching time (specified to $0.3 \mathrm{~s}$ ). To compensate for this inaccuracy, we characterize the DA wells before the cleaved edge overgrowth is performed to determine the actual transition energy and to adjust the thickness of the overgrown well correspondingly.

The nominal 7\% DA of ASW2 was grown by dividing the $180 \AA$ wells into 20 sublayers of $9 \AA$. Each sublayer is then divided into a GaAs layer and an $\mathrm{Al}_{0.3} \mathrm{Ga}_{0.7} \mathrm{As}$ layer. The width of the $\mathrm{Al}_{0.3} \mathrm{Ga}_{0.7}$ As layer is given by the ratio between the intended $\mathrm{Al}$ content of the $\mathrm{DA}$ to the $\mathrm{Al}$ content of the barrier, multiplied by the width of the sublayer. This gives $2.1 \AA$ for the $\mathrm{Al}_{0.3} \mathrm{Ga}_{0.7}$ As layer, leaving $6.9 \AA$ for the GaAs layer. The Al shutter was opened 20 times for $0.64 \mathrm{~s}$ per quantum well. The rotation of the substrate during growth was fast enough to give one rotation per $2.1 \AA$ $\mathrm{Al}_{0.3} \mathrm{Ga}_{0.7} \mathrm{As}$ layer. The barrier width is $320 \AA$ in order to decouple the $T$-wire states. The total thickness of the (001) structure is $2.5 \mu \mathrm{m}$. The (001) structure of sample ASW1 was made similarly, with a nominal $12 \%$ DA in the 120 - $\AA$ thick wells, which were divided into 10 sublayers. This structure consists of 20 wells separated by 200 - $\AA$-thick barriers and is $0.64 \mu \mathrm{m}$ thick.

Low-temperature photoluminescence (PL) measurements were performed with the samples mounted in a continuous-flow cryostat using $\mathrm{He}-\mathrm{Ne}(632.8 \mathrm{~nm})$ or Ar-ion $(488 \mathrm{~nm})$ laser excitation, both with an excitation intensity of $0.1 \mathrm{~W} / \mathrm{cm}^{2}$. The PL was dispersed in a spectrometer and detected by a photomultiplier using photon counting techniques. To adjust the sample position, the PL was imaged with a video camera.

The PL spectra of the (001) structures, measured at $4 \mathrm{~K}$, are displayed in Fig. 2 and show the heavy-hole exciton emission from the wells. The linewidths are 3 and $5 \mathrm{meV}$ for the DA of ASW2 and ASW1, respectively. The transition energies of the DA wells are mainly given by the alloy bandgap, ${ }^{9} E_{g}=1.519+1.155 x+0.37 x^{2}$, because the quantization energies for the large well widths are low, e.g., 10 $\mathrm{meV}$ for the $180 \AA$ well of ASW2. From the transition energies in Fig. 2, we estimate a higher Al content of about 9\% and $14 \%$ instead of the nominal $7 \%$ and $12 \%$.

Taking the above characterization into account, the cleaved edge overgrowth of the (110) oriented GaAs/ $\mathrm{Al}_{0.3} \mathrm{Ga}_{0.7} \mathrm{As}$ well is designed so that the transition energy of the well coincides with the transition energy of the experimentally realized (001) wells. The transition energies of the (110) oriented GaAs/ $/ \mathrm{Al}_{0.3} \mathrm{Ga}_{0.7}$ As wells, as a function of well width, have been calculated previously and experimentally verified. $^{10}$

The substrates of the (001) structures were lapped to a thickness of $90 \mu \mathrm{m}$ to ease the cleaving. Pieces of $5 \times 6$

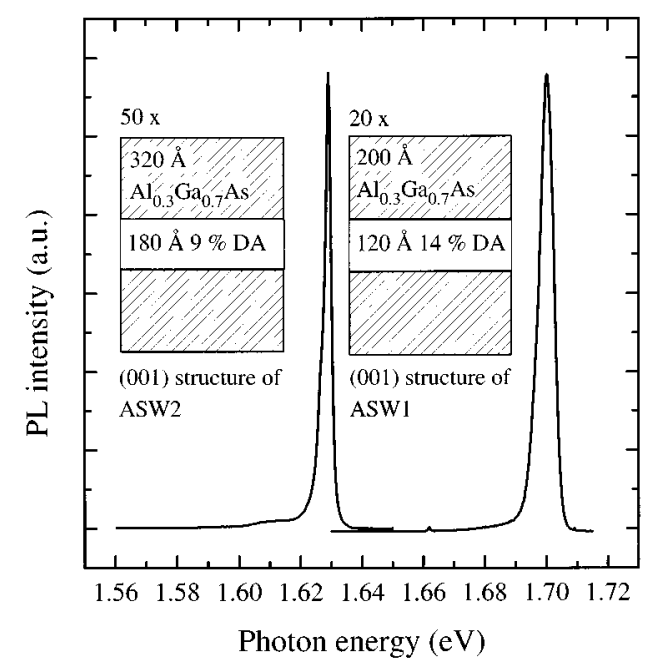

FIG. 2. PL spectra of the (001) structures with a DA in the wells recorded at $4 \mathrm{~K}$. Structure parameters are shown.

$\mathrm{mm}^{2}$ were mounted vertically on a special sample holder ${ }^{5}$ and cleaved in the MBE buffer chamber to avoid oxidation of the cleaved layers. The overgrowth was started within a few minutes after the cleavage. For ASW1, the overgrowth is a $25 \AA$ well, a $200 \AA$ barrier, and a $100 \AA$ GaAs layer. For ASW2, it is a $43 \AA$ well, a $320 \AA$ barrier, and a $1500 \AA$ GaAs cap.

Different (110) growth conditions were tested for the two samples. For ASW1, a low substrate temperature of about $460{ }^{\circ} \mathrm{C}$ and a low GaAs growth rate of $0.5 \mu \mathrm{m} / \mathrm{h}$ was used. The V/III beam equivalent pressure (BEP) ratio was 30. For ASW2, the GaAs growth rate was $0.45 \mu \mathrm{m} / \mathrm{h}$ and the substrate temperature was increased to about $500{ }^{\circ} \mathrm{C}$ to compensate for a possible temperature difference between the cleaved edge and the planar substrate. ${ }^{11}$ The temperatures were measured by an infrared pyrometer on a planar reference substrate.

The PL spectra of the two $T$-wire structures are shown in Fig. 3. The PL intensity of the wires is almost constant be-

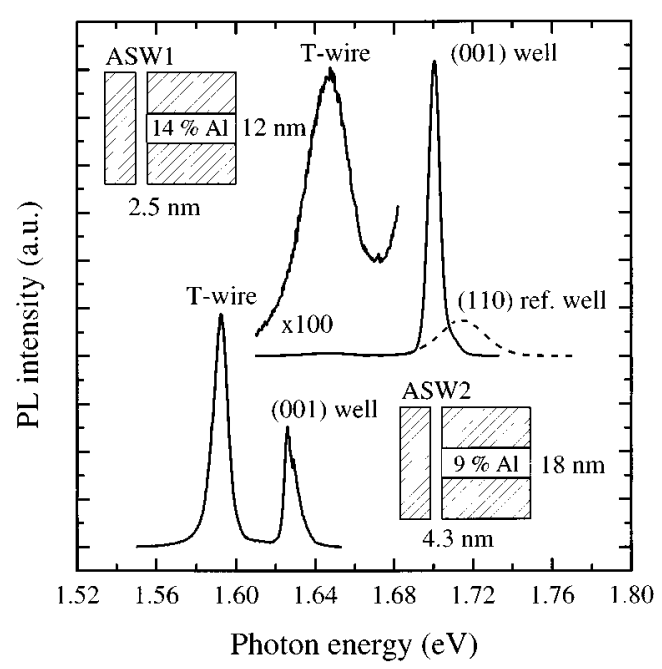

FIG. 3. Sample structures and PL spectra of the $T$-wire structures ASW1 and ASW2 recorded at $40 \mathrm{~K}$ with $\mathrm{He}-\mathrm{Ne}$ and argon-ion laser excitation, respectively. The dashed curve is a PL spectrum of a (110) reference structure for the overgrowth of ASW1. 
tween 4 and $40 \mathrm{~K}$ while the PL of the wells is significantly lowered. This enhances the $T$-wire intensity relative to the well intensity at $40 \mathrm{~K}$. The spectrum of ASW1 shows the heavy-hole exciton emission from the wells, and the $T$-wire emission. The dashed curve is the PL spectrum of a reference structure grown on a planar (110) substrate. The transition energies of the (001) and (110) oriented wells are matching within $10 \mathrm{meV}$ and the $T$-wire states are confined by $54 \mathrm{meV}$ as compared to the (001) well states. The calculated confinement energy between the well and wire states, from Fig. 1(a), is $35 \mathrm{meV}$ for the pre-designed structure. For the actual structure ASW1, the calculated confinement is $39 \mathrm{meV}$.

For ASW2, the $T$-wire PL is separated by $37 \mathrm{meV}$ from the PL of the (001) wells, and the temperature dependence above $50 \mathrm{~K}$ (not shown) of the $T$-wire PL intensity shows an activation energy of $32 \mathrm{meV}$. The $T$-wire confinement energy is thus between 32 and $37 \mathrm{meV}$, while the calculated $T$-wire confinement energy of ASW2 is $28 \mathrm{meV}$.

The difference between the calculated and measured $T$-wire confinement energies may have several reasons. First, the accuracy of the calculation is limited by the accuracy of the material parameters, the theoretical model, and our knowledge about the precise shape of the $T$-wire structure. Second, Coulomb interaction and strain shifts are neglected in the calculations of both the well and $T$-wire states.

The exciton binding energy of the 120 (180) $\AA$ thick (001) well is about $9(8) \mathrm{meV},{ }^{12}$ respectively. Thus, a $T$-wire exciton binding energy of approximately 25 (17) $\mathrm{meV}$ would explain the enhanced confinement in terms of the Coulomb interaction. Previously, $T$-wire exciton binding energies of 20 and $16 \mathrm{meV}$ have been calculated ${ }^{1}$ for structures which are different, but similar to the structures ASW1 and ASW2, in fair agreement with the values 25 and $17 \mathrm{meV}$. Recently, $T$-wire exciton binding energies of 17 and $27 \mathrm{meV}$ have been reported for GaAs $T$-wires with $\mathrm{Al}_{0.3} \mathrm{Ga}_{0.7}$ As and AlAs barriers, respectively. ${ }^{7}$ In general, these values are higher than expected from calculations of the exciton binding energy in $T$-wire structures. ${ }^{13}$ Also, other mechanisms such as strain shifts and unequal overgrowth on well and barrier regions of the cleaved (001) multiple quantum well could account for the enhanced $T$-wire confinements compared to calculation.

The PL linewidth of the (110) reference is $24 \mathrm{meV}$ due to the narrow well width. ${ }^{10}$ Since the $T$-wire state is a mixture of the (001) and (110) well states, the linewidth is expected to be in-between the linewidths of these wells. In fact, the $20 \mathrm{meV} T$-wire PL linewidth of ASW1 is in good agreement with the calculated $75 \%$ of the linewidth of the (110) well. ${ }^{8}$ In the spectra of ASW2, the $T$-wire linewidth is only $7 \mathrm{meV}$. We estimate a $10 \mathrm{meV}$ PL linewidth of the $43 \AA$
(110) well from previous studies of the (110) wells. ${ }^{10}$ The linewidth of the $T$-wire emission is thus also about $75 \%$ of the PL linewidth of the (110) well.

The differences in the relative PL intensities for ASW1 and ASW2 are caused by the different substrate temperature and cap layer thickness in the overgrowth. This has been verified by a regrowth of the structure ASW1 using only a higher substrate temperature in one case, and in the other case also a thicker GaAs cap layer, as in the overgrowth of ASW2. The relative wire intensity was enhanced by a factor of 4 (100), in the first (second) case, respectively. The strong dependence of the wire PL on the cap thickness was not expected, because the tunneling of the carriers to the surface is controlled by the barrier thickness. It may, however, be related to the influence of surface fields or to a change of the radiative coupling in the proximity of the surface.

In conclusion, a systematic approach to improve the confinement energy of $T$-wires has been demonstrated. The sample parameters were pre-designed by the use of a numerical calculation of the confined $T$-wire states. After PL characterization of the (001) oriented DA wells, the overgrown well thickness was adjusted to match the (110) and (001) transition energies. By this procedure, a confinement energy of $54 \mathrm{meV}$ is achieved, which is significantly larger than the previously reported $38 \mathrm{meV}^{7}$

Helpful discussions with C. B. Sørensen on the MBE growth are acknowledged. This work was supported by the Danish Ministries of Research and Industry in the framework of CNAST.

${ }^{1}$ Y. C. Chang, L. L. Chang, and L. Esaki, Appl. Phys. Lett. 47, 1324 (1985).

${ }^{2}$ L. N. Pfeiffer, K. W. West, H. L. Störmer, J. P. Eisenstein, K. W. Baldwin, D. Gershoni, and J. Spector, Appl. Phys. Lett. 56, 1697 (1990).

${ }^{3}$ D. Gershoni, J. S. Weiner, S. N. G. Chu, G. A. Baraff, J. M. Vandenberg, L. N. Pfeiffer, K. W. West, R. A. Logan, and T. Tanbuk-Ek, Phys. Rev. Lett. 65, 1631 (1990).

${ }^{4}$ A. R. Goñi, L. N. Pfeiffer, K. W. West, A. Pinczuk, H. U. Baranger, and H. L. Störmer, Appl. Phys. Lett. 61, 1956 (1992).

${ }^{5}$ L. N. Pfeiffer, H. L. Störmer, K. W. Baldwin, K. W. West, A. R. Goñi, A. Pinczuk, R. C. Ashoori, M. M. Dignam, and W. Wegscheider, J. Cryst. Growth 127, 849 (1993).

${ }^{6}$ W. Wegscheider, L. N. Pfeiffer, M. M. Dignam, A. Pinczuk, K. W. West, S. L. McCall, and R. Hull, Phys. Rev. Lett. 71, 4071 (1993).

${ }^{7}$ T. Someya, H. Akiyama, and H. Sakaki, Phys. Rev. Lett. 76, 2965 (1996).

${ }^{8}$ W. Langbein, H. Gislason, and J. M. Hvam, Phys. Rev. B (to be published).

${ }^{9}$ S. Adachi, Properties of Aluminum Gallium Arsenide (INSPEC, London, 1993).

${ }^{10}$ H. Gislason, C. B. Sørensen, and J. M. Hvam, Appl. Phys. Lett. 69, 800 (1996).

${ }^{11}$ T. Someya, H. Akiyama, and H. Sakaki, J. Appl. Phys. 79, 2522 (1996).

${ }^{12}$ E. S. Koteles and J. Y. Chi, Phys. Rev. B 37, 6332 (1988).

${ }^{13}$ W. Langbein and J. M. Hvam, (unpublished). 